\title{
Hubungan Karakteristik dan Tingkat Pengetahuan Petugas Imunisasi terhadap Praktik Penyimpanan dan Transportasi Vaksin Imunisasi di Tingkat Puskesmas Kota Padang Tahun
} 2014

\author{
Nadia Rahmah ${ }^{1}$, Putri Sri Lasmini ${ }^{2}$, Rahmatini ${ }^{3}$
}

\begin{abstract}
Abstrak
Rantai dingin sangat penting dipertahankan selama distribusi dan penyimpanan vaksin untuk mencapai efektifitas vaksin. Petugas Imunisasi di layanan primer harus memiliki pengetahuan dan pemahaman yang baik mengenai transportasi dan penyimpanan vaksin. Penelitian dilaksanakan di seluruh puskesmas Kota Padang pada Maret 2014, dengan menggunakan desain cross sectional. Jumlah sampel adalah 21petugas imunisasi dengan teknik total sampling. Pengumpulan data dilakukan dengan menggunakan kuesioner dan observasi. Hasil penelitian didapatkan responden dengan pengetahuan yang baik tentang penyimpanan dan transportasi vaksin sebesar $61,9 \%$ dan praktik penyimpanan dan transportasi vaksin di Puskesmas yang baik sebesar $61,9 \%$. Berdasarkan uji statistik, didapatkan tidak adanya hubungan umur, tingkat pendidikan, masa kerja dan pengalaman pelatihan petugas imunisasi dengan praktik penyimpanan dan transportasi vaksin di Puskesmas tetapi terdapat hubungan pengetahuan petugas dengan praktik. Berdasarkan hasil penelitian disimpulkan bahwa tidak terdapatnya hubungan karakteristik petugas imunisasi dengan praktik penyimpanan dan transportasi vaksin dan terdapatnya hubungan bermakna antara pengetahuan petugas dengan praktik penyimpanan dan transportasi vaksin di Puskesmas Kota Padang.
\end{abstract}

Kata kunci: karakteristik, pengetahuan, penyimpanan, transportasi vaksin

\begin{abstract}
Preserving the cold chain during distribution and storage is critical to achieve the effectiveness of the vaccine. Immunization workers in primary health care should have a good knowledge and understanding about the handling and storage of the vaccine. The experiment was conducted in all health centers Padang in 2014 March, using a crosssectional design. Total samples 21 immunization workers with total sampling. The data was collected using questionnaires and observation. The results showed respondents with good knowledge about vaccine storage and handling of $61.9 \%$ and vaccine storage and handling practices in health centers of $61.9 \%$ which is good. Based on statistical tests, found no rellation between age, education, years of working and training experience of immunization workers with vaccine storage and handling practices in health care but a significant correlation between knowledge with practice. Based on the results of the study concluded that the absence of the relations between characteristic immunization workers with vaccine storage and handling practices and a significant correlation between knowledge workers with practical storage and handling of vaccines at the health center of Padang.
\end{abstract}

Keywords: characteristics, knowledge, storage, handling of vaccines

Affiliasi penulis: 1. Pendidikan Dokter FK UNAND (Fakultas Kedokteran Universitas Andalas Padang), 2. Bagian Obstetri dan Ginekologi FK UNAND, 3.Bagian Farmakologi FK UNAND
Korespondensi: Nadia Rahmah, Email :

n_nadiarahmah@yahoo.com Telp: 085263012277 


\section{PENDAHULUAN}

Program imunisasi nasional yang dikenal sebagai Pengembangan Program Imunisasi (PPI) atau Expanded Program on Immunization (EPI) merupakan salah satu upaya preventif yang telah terbukti sangat efektif menurunkan angka kesakitan dan angka kematian serta kecacatan pada bayi dan balita. Imunisasi yang termasuk dalam PPI adalah imunisasi dasar lengkap yang diberikan pada bayi usia $0-9$ bulan yaitu imunisasi BCG, polio, DTP, campak dan hepatitis $B .1$

Keberhasilan program imunisasi tergantung pada dua hal yaitu tingginya tingkat cakupan vaksinasi dan vaksin yang efektif. Mempertahankan rantai dingin selama distribusi dan penyimpanan sangat penting dalam mencapai efektifitas vaksin. Penyimpanan sebagian besar vaksin umumnya direkomendasikan pada suhu $2^{\circ} \mathrm{C}-8^{\circ} \mathrm{C}$ dan tidak boleh terkena suhu beku. Semakin lama vaksin terpapar panas atau dingin yang berlebihan, semakin mengurangi potensi vaksin tersebut. Jika rantai dingin vaksin tidak dipelihara dengan baik, semua potensi vaksin akan hilang dan vaksin tidak dapat digunakan. Vaksin dapat dikategorikan sebagai heat sensitive atau freeze sensitive. Vaksin heat sensitive termasuk vaksin hidup dilemahkan (live attenuated) yang stabil pada suhu beku tapi kehilangan potensi setelah terpapar suhu di atas kisaran yang direkomendasikan. Vaksin golongan freeze sensitive menggunakan bahan tambahan berupa garam aluminium yang akan mengendap saat terpapar suhu beku, sehingga dapat merusak bahan tambahan dan potensi vaksin. ${ }^{2-5}$

Pemberian vaksin yang salah dapat menambah jumlah pasien yang menderita penyakit yang dapat dicegah dengan imunisasi (PD3I). Kegagalan untuk mematuhi prosedur penyimpanan dan penanganan dapat mengurangi potensi vaksin, sehingga menghasilkan respon imun yang tidak adekuat dan perlindungan terhadap penyakit yang dapat dicegah dengan vaksin tidak tercapai secara optimal. ${ }^{6}$

Adanya laporan mengenai vaksin yang disimpan secara tidak benar, sehingga memerlukan vaksin pengganti dan melakukan imunisasi kembali. Jika prosedur penyimpanan dan distribusi vaksin telah dilakukan secara benar kekhawatiran tentang apa yang harus dilakukan pada vaksin yang sudah tidak dapat digunakan dan kerugian finansial terhadap vaksin tersebut dapat diminimalkan. Dalam General Recommendations on Immunization, The Advisory Committee on Immunization Practices (ACIP) merekomendasikan vaksin yang terkena paparan suhu melebihi dari batasan dan secara tidak sengaja diberikan, maka pemberian vaksin harus diulang. ${ }^{5,6}$

Reaksi simpang yang dikenal sebagai Kejadian Ikutan Pasca Imunisasi (KIPI) atau Adverse Events Following Immunization (AEFI) adalah kejadian medik yang berhubungan dengan imunisasi baik berupa efek vaksin ataupun efek samping vaksin. Persepsi awam dan juga kalangan petugas kesehatan, menganggap semua kelainan dan kejadian yang dihubungkan dengan imunisasi sebagai reaksi alergi terhadap vaksin. Sesuai telaah laporan KIPI oleh Vaccine Safety Committee, Institute of Medicine (IOM) USA menyatakan bahwa kejadian KIPI tersering akibat imunisasi adalah akibat kesalahan prosedur dan teknik pelaksanaan (programmatic errors). Masalah program dan teknik pelaksanaan imunisasi meliputi kesalahan program penyimpanan, pengelolaan dan tata laksana pemberian vaksin. ${ }^{1}$

Tahun 2009 cakupan imunisasi di Ulumanda Kabupaten Majene Sulawesi Barat adalah 0\%, dan di Puskesmas Majene ditemukan vaksin yang rusak sebelum digunakan. Vaksin telah ditempatkan dalam pendingin tetapi kesalahan terjadi dimulai dari distribusi sampai pada proses penyimpanan, sehingga kondisi vaksin menjadi tidak stabil dan tidak layak digunakan lagi. Berdasarkan data tahun 2010, sekitar 397 botol vaksin dilaporkan rusak dan 105 botol vaksin dilaporkan kadaluarsa, sehingga tidak dapat digunakan. ${ }^{7}$

Kualitas vaksin adalah tanggung jawab bersama semua pihak, mulai dari produksi sampai pemberian vaksin. Rantai vaksin dijaga mulai dari distribusi langsung dari produsen ke gudang vaksin Depkes RI, dialokasikan ke Dinkes provinsi, dari Dinkes provinsi didistribusikan ke Dinkes kabupaten / kota, setelah itu distribusi dari kabupaten / kota ke Puskesmas. Puskesmas merupakan tempat penyimpanan terakhir vaksin sebelum pemberian vaksin terhadap sasaran.Proses produksi di pabrik umumnya memiliki prosedur khusus sesuai dengan ketentuan GMP (Good Manufacturing Practices) 
dibawah pengawasan NRA (National Regulatory Authority) setempat. Oleh karena itu monitoring kualitas pengelolaan vaksin lebih ditujukan pada pengelolaan vaksin di gudang penyimpanan vaksin di tingkat primer sampai di unit pelayanan seperti Puskesmas. ${ }^{4,8,9}$

Rantai dingin harus tetap terjaga sampai pada tahap pemberian. Pada penyedia layanan primer harus memiliki pengetahuan dan pemahaman yang baik dalam mengelola rantai vaksin. Tenaga kesehatan di layanan primer harus paham benar mengenai transportasi dan penyimpanan vaksin sampai vaksin itu diberikan. Didapatkan dari hasil penelitian sebelumnya bahwa pengetahuan petugas merupakan salah satu faktor risiko yang berpengaruh terhadap kualitas pengelolaan vaksin..$^{10,11}$

Saat ini belum ada penelitian tentang penyimpanan dan transportasi vaksin imunisasi di Puskesmas Kota Padang, oleh karena itu perlu dilakukan penelitian tentang hubungan karakteristik dan tingkat pengetahuan petugas imunisasi terhadap praktik penyimpanan dan transportasi vaksin imunisasi di tingkat puskesmas Kota Padang tahun 2014.

\section{METODE}

Penelitian ini dilakukan di seluruh puskesmas di Kota Padang dari Januari 2014 sampai Maret 2014 Subjek dalam penelitian ini sebanyak 22 orang yang merupakan petugas imunisasi puskesmas yang memenuhi kriteria inklusi. Pemilihan subjek dilakukan secara total sampling. Pengambilan data menggunakan kuesioner dan observasi. Instrumen yang digunakan dalam penelitian adalah kuesioner dan penilaian observasi. Data yang diperoleh diolah dengan menggunakan sistem komputerisasi kemudian dianalisis dengan uji chi-square.

\section{HASIL}

Karakteristik petugas imunisasi tersebut dapat dilihat pada Tabel 1 menggambarkan responden berumur $\leq 45$ tahun sebanyak 15 responden $(71,4 \%)$ dan $>45$ tahun sebanyak 6 responden (28,6\%). Berdasarkan hasil penelitian dari 21 responden ratarata responden berumur 40 tahun.
Tabel 1. Karakteristik petugas imunisasi Puskesmas

\begin{tabular}{|c|c|c|c|}
\hline No. & $\begin{array}{c}\text { Karakteristik Petugas } \\
\text { Imunisasi }\end{array}$ & f & $\%$ \\
\hline \multirow[t]{4}{*}{1.} & Umur: & & \\
\hline & a. $\leq 45$ tahun & 15 & 71,4 \\
\hline & b. $>45$ tahun & 6 & 28,6 \\
\hline & Total & 21 & 100,0 \\
\hline \multirow[t]{4}{*}{2.} & Tingkat Pendidikan : & & \\
\hline & a. Sarjana & 1 & 4,8 \\
\hline & b. Diploma & 20 & 95,2 \\
\hline & Total & 21 & 100,0 \\
\hline \multirow[t]{4}{*}{3.} & Masa Kerja : & & \\
\hline & a. $\quad \geq 1$ tahun & 16 & 76,2 \\
\hline & b. $<1$ tahun & 5 & 23,8 \\
\hline & Total & 21 & 100,0 \\
\hline \multirow[t]{4}{*}{4.} & Pengalaman Pelatihan & & \\
\hline & a. Pernah & 17 & 81,0 \\
\hline & b. Belum & 4 & 19,0 \\
\hline & Total & 21 & 100,0 \\
\hline
\end{tabular}

Pada umumnya seluruh responden telah memiliki tingkat pendidikan yang tinggi, yaitu tamatan diploma dan sarjana. Sebanyak 16 responden $(76,2 \%)$ telah bekerja di Puskesmas sebagai petugas imunisasi selama lebih dari 1 tahun dan 17 responden $(81,0 \%)$ telah mendapatkan pelatihan mengenai penyimpanan dan transportasi vaksin imunisasi.

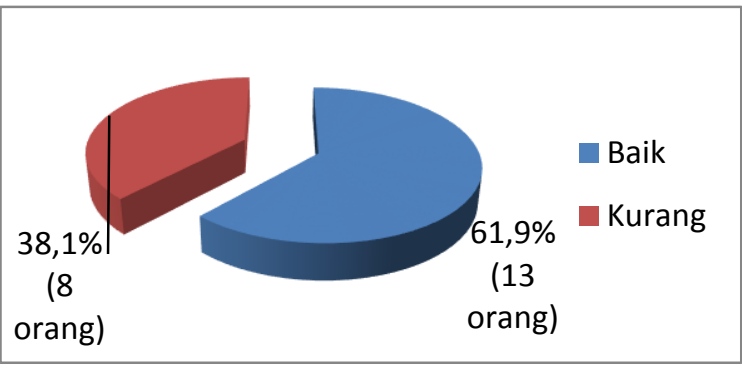

Gambar 1. Distribusi pengetahuan petugas imunisasi tentang penyimpanan dan transportasi vaksin

Gambar 1 menunjukkan bahwa dari 21 responden sebanyak 13 responden (61,9\%) memiliki pengetahuan tentang penyimpanan dan transportasi vaksin imunisasi yang baik dan sebanyak 8 responden $(38,1 \%)$ memiliki pengetahuan kurang. 


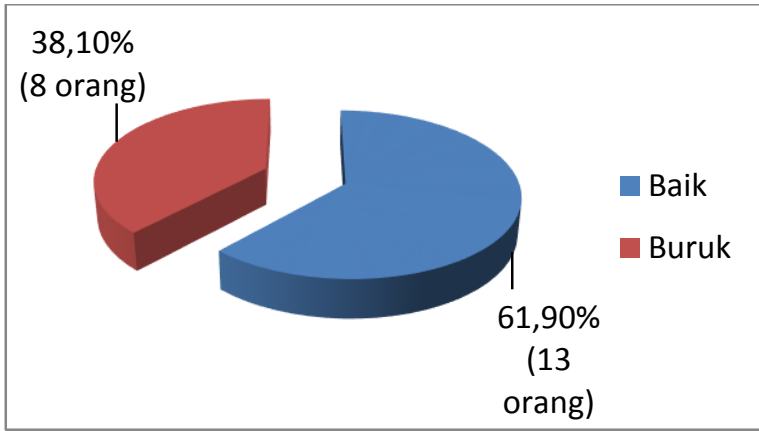

Gambar 2. Distribusi praktik penyimpanan dan transportasi vaksin di puskesmas Kota Padang

Gambar 2 menunjukkan bahwa dari 21 Puskesmas sebanyak 13 Puskesmas (61,9\%) memiliki praktik yang baik dalam penyimpanan dan transportasi vaksin imunisasi dan praktik yang buruk sebanyak 8 puskesmas $(38,1 \%)$.

Tabel 2. Hubungan karakteristik dan pengetahuan petugas imunisasi terhadap praktik penyimpanan dan transportasi vaksin imunisasi

\begin{tabular}{|c|c|c|c|c|c|c|c|}
\hline \multirow{3}{*}{ Variabel } & \multicolumn{4}{|c|}{ Praktik } & \multicolumn{2}{|c|}{ Total } & \multirow{3}{*}{ p } \\
\hline & \multicolumn{2}{|c|}{ Baik } & \multicolumn{2}{|c|}{ Buruk } & \multirow{2}{*}{ f } & \multirow{2}{*}{$\%$} & \\
\hline & $F$ & $\%$ & $f$ & $\%$ & & & \\
\hline \multicolumn{8}{|l|}{ Umur } \\
\hline$\leq 45$ th & 9 & 60,0 & 6 & 40,0 & 15 & 100 & \multirow{3}{*}{1,000} \\
\hline$>45$ th & 4 & 66,7 & 2 & 33,3 & 6 & 100 & \\
\hline Jumlah & 13 & 61,9 & 8 & 38,1 & 21 & 100 & \\
\hline
\end{tabular}

\begin{tabular}{|c|c|c|c|c|c|c|c|}
\hline \multicolumn{8}{|c|}{ Pendidikan } \\
\hline Sarjana & 1 & 100 & 0 & 0 & 1 & 100 & \multirow{3}{*}{ - } \\
\hline$\overline{\text { Diploma }}$ & 12 & 60,0 & 8 & 40,0 & 20 & 100 & \\
\hline Jumlah & 13 & 61,9 & 8 & 38,1 & 21 & 100 & \\
\hline \multicolumn{8}{|c|}{ Masa Kerja } \\
\hline$\geq 1$ th & 9 & 56,3 & 7 & 43,7 & 16 & 100 & \multirow{3}{*}{0,606} \\
\hline$<1$ th & 4 & 80,0 & 1 & 20,0 & 5 & 100 & \\
\hline Jumlah & 13 & 61,9 & 8 & 38,1 & 21 & 100 & \\
\hline \multicolumn{8}{|c|}{ Pelatihan } \\
\hline$\overline{\text { Pernah }}$ & 10 & 58,8 & 7 & 41,2 & 17 & 100 & \multirow{3}{*}{1,000} \\
\hline Belum & 3 & 75,0 & 1 & 25,0 & 4 & 100 & \\
\hline Jumlah & 13 & 61,9 & 8 & 38,1 & 21 & 100 & \\
\hline \multicolumn{8}{|c|}{ Pengetahuan } \\
\hline$\overline{\text { Baik }}$ & 11 & 84,6 & 2 & 15,4 & 13 & 100 & \multirow{3}{*}{0,018} \\
\hline Kurang & 2 & 25,0 & 6 & 75,0 & 8 & 100 & \\
\hline Jumlah & 13 & 61,9 & 8 & 38,1 & 21 & 100 & \\
\hline
\end{tabular}

Berdasarkan Tabel 2 dapat dilihat bahwa dari 15 petugas imunisasi yang berusia $\leq 45$ tahun, sebanyak 9 petugas $(60,0 \%)$ yang memiliki praktik baik dan 6 petugas $(40,0 \%)$ yang memiliki praktik buruk. Sebaliknya, dari 6 petugas yang berusia lebih dari 45 tahun, sebanyak 4 petugas $(66,7 \%)$ yang memiliki praktik baik dan sebanyak 2 petugas (33,3\%) yang memiliki praktik buruk. Hasil uji statistik chisquare test dengan fisher's exact test diperoleh nilai $P=1,000(P>0,05)$ dapat disimpulkan bahwa tidak terdapat pengaruh yang signifikan antara umur petugas imunisasi dengan praktik penyimpanan dan transportasi vaksin imunisasi di tingkat puskesmas Kota Padang.

Tabel 2 memperlihatkan bahwa hanya satu petugas imunisasi tamatan sarjana dan memiliki praktik baik. Dari 20 petugas imunisasi tamatan diploma, 12 petugas $(60,0 \%)$ yang memiliki praktik baik dan 8 petugas $(40,0 \%)$ yang memiliki praktik buruk.Dalam hal ini, uji statistik chi-square tidak dapat diperoleh nilai $\mathrm{p}$ sebab ada satu kotak tabel dengan nilai frekuensi kenyataan atau disebut juga Actual Count (F0) sebesar 0 (Nol). Dapat disimpulkan bahwa tidak terdapat pengaruh yang signifikan antara pendidikan petugas imunisasi dengan praktik penyimpanan dan transportasi vaksin imunisasi di tingkat puskesmas Kota Padang, hal ini disebabkan karena hampir keseluruhan petugas imunisasi merupakan tamatan diploma.

Hasil penelitian ini memperlihatkan bahwa dari 16 petugas imunisasi yang sudah bekerja lebih dari 1 tahun, sebanyak 9 petugas $(56,3 \%)$ yang memiliki praktik baik dan 7 petugas (43,7\%) yang memiliki praktik buruk. Sebaliknya, dari 5 petugas yang masa kerja kurang dari 1 tahun, sebanyak 4 petugas $(80,0 \%)$ yang memiliki praktik baik dan sebanyak 1 petugas $(20,0 \%)$ yang memiliki praktik buruk. Hasil uji statistik chi-square test dengan fisher's exact test diperoleh nilai $P=0,606(P>0,05)$ dapat disimpulkan bahwa tidak terdapat pengaruh yang signifikan antara masa kerja petugas imunisasi dengan praktik penyimpanan dan transportasi vaksin imunisasi di tingkat puskesmas Kota Padang.

Dari 17 petugas imunisasi yang telah mendapat pelatihan pengelolaan vaksin, sebanyak 10 petugas 
$(58,8 \%)$ yang memiliki praktik baik dan tujuh petugas $(41,2 \%)$ yang memiliki praktik buruk. Empat petugas yang belum mendapat pelatihan, sebanyak tiga petugas $(75,0 \%)$ yang memiliki praktik baik dan sebanyak 1 petugas (25,0\%) yang memiliki praktik buruk. Hasil uji statistik chi-square test dengan fisher's exact test diperoleh nilai $p=1,000(p>0,05)$ dapat disimpulkan bahwa tidak terdapat pengaruh yang signifikan antara pengalaman pelatihan petugas imunisasi dengan praktik penyimpanan dan transportasi vaksin imunisasi di tingkat puskesmas Kota Padang.

Berdasarkan Tabel 2 dapat dilihat bahwa dari 13 petugas imunisasi yang memiliki pengetahuan baik, sebanyak 11 petugas (84,6\%) yang memiliki praktik baik dan 2 petugas (15,4\%) yang memiliki praktik buruk. Sebaliknya, dari 8 petugas yang memiliki pengetahuan kurang, sebanyak 2 petugas (25,0\%) yang memiliki praktik baik dan sebanyak 6 petugas $(75,0 \%)$ yang memiliki praktik buruk. Hasil uji statistik chi-square test dengan fisher's exact test diperoleh nilai $p=0,018(p>0,05)$ dapat disimpulkan bahwa terdapat pengaruh yang signifikan antara pengetahuan petugas imunisasi dengan praktik penyimpanan dan transportasi vaksin imunisasi di tingkat puskesmas Kota Padang.

\section{PEMBAHASAN}

Berdasarkan hasil penelitian menunjukkan tingkat pengetahuan rata-rata responden adalah baik. Beberapa pertanyaan dalam kuesioner tentang pengetahuan penyimpanan dan transportasi vaksin imunisasi ditemukan kurang dari $50 \%$ petugas imunisasi yang menjawab dengan benar. Pertanyaan tersebut adalah mengenai kegunaan indikator VVM, fungsi Freeze Tag, vaksin yang dapat disimpan dalam suhu $0^{\circ} \mathrm{C}$, masa penyimpanan vaksin polio setelah dibuka, klasifikasi vaksin menurut cara pembuatannya dan suhu penyimpanan vaksin. Kemungkinan penyebab hal ini adalah kurang terpaparnya petugas imunisasi dengan teori - teori mengenai vaksin imunisasi, kurangnya kesadaran petugas imunisasi untuk memahami praktik penyimpanan vaksin imunisasi dan tidak tersedianya alat seperti freeze tag di Puskesmas sehingga petugas tidak mengetahui fungsi dari alat tersebut.
Pengetahuan adalah hasil tahu dari seseorang yang terjadi setelah orang tersebut melakukan penginderaan terhadap suatu objek tertentu. Seseorang dengan pengetahuan yang cukup dapat memahami sesuatu itu baik atau buruk, sehingga dapat dikatakan bahwa pengetahuan dapat menentukan perilaku seseorang. Dalam hal ini dapat dinyatakan bahwa pengetahuan dapat menentukan perilaku petugas imunisasi dalam melakukan praktik penyimpanan dan transportasi dengan benar. ${ }^{12}$ Menurut Kristini dalam penelitiannya pada tahun 2008 menyatakan bahwa pengetahuan merupakan faktor risiko yang berpengaruh terhadap kualitas pengelolaan vaksin. Petugas dengan pengetahuan kurang mempunyai risiko 3,7 kali menyebabkan kualitas pengelolaan vaksin menjadi buruk dibanding petugas dengan pengetahuan baik. ${ }^{13}$ Hasil penelitian Carlos dan Bjune yang dilakukan pada tahun 2007 di Niassa, didapatkan bahwa terdapat pengetahuan dan praktik yang buruk dalam mengelola vaksin imunisasi di pusat pelayanan primer. ${ }^{14}$

Berdasarkan hasil penelitian menunjukan praktik rata-rata puskesmas adalah baik. Namun ada satu penilaian mengenai praktik penyimpanan dan transportasi vaksin imunisasi ditemukan kurang dari $50 \%$ puskesmas yang melaksanakan dengan benar, yaitu mengenai ketersediaan termostat yang diletakkan di sela antara kotak vaksin. Penyebab hal ini adalah rusak atau tidak tersedianya termostat di puskesmas, sehingga puskesmas hanya menggunakan pengukur suhu dari lemari es. Puskesmas yang tidak memiliki termostat sebanyak 7 puskesmas dan puskesmas dengan termostat rusak sebanyak 5 puskesmas. Penelitian ini sejalan dengan yang dilakukan oleh Widsanugron pada tahun 2011 di Thailand, tentang pengetahuan dan praktik petugas kesehatan terkait pengembangan program imunisasi. Dalam praktik pengelolaan sistem rantai dingin di pelayanan kesehatan primer didapatkan hasil praktik yang benar $78,3 \% .^{11}$

Perilaku adalah hasil antara stimulus (faktor eksternal) dengan respons (faktor internal). Menurut WHO yang dikutip Notoadmodjo dalam menganalisis perilaku seseorang, ada beberapa faktor yang dapat mempengaruhi perilaku seseorang yaitu pemikiran dan perasaan, pengetahuan, kepercayaan, sikap, 
tokoh penting sebagai panutan dan sumber daya seperti fasilitas. ${ }^{12}$ Menurut Kristini dalam penelitiannya pada tahun 2008, ada beberapa faktor yang dapat mempengaruhi kualitas pengelolaan vaksin program imunisasi diantaranya yaitu pengetahuan petugas yang kurang mempunyai risiko 31,6 kali menyebabkan kualitas vaksin menjadi buruk, mempunyai pedoman pengelolaan vaksin, lemari es yang tidak khusus, mempunyai termometer dalam lemari es, kesalahan transportasi vaksin, dan komitmen petugas. ${ }^{13}$

Berdasarkan Tabel 2 dapat dilihat bahwa praktik penyimpanan dan transportasi vaksin yang baik terbanyak pada kelompok umur $\leq 45$ tahun (60,0\%). Dari hasil uji statistik chi-square test dengan fisher's exact test diperoleh nilai $p=1,000(p>0,05)$ dapat disimpulkan bahwa tidak terdapat pengaruh yang signifikan antara umur petugas imunisasi dengan praktik penyimpanan dan transportasi vaksin imunisasi. Hal ini menunjukkan bahwa umur tidak benar-benar mempengaruhi petugas imunisasi untuk melakukan praktik yang benar. Terdapat 6 orang $(40,0 \%)$ petugas imunisasi berumur $\leq 45$ tahun yang memiliki praktik buruk. Hal ini mungkin disebabkan karena kurangnya pengetahuan petugas imunisasi tentang penyimpanan dan transportasi vaksin imunisasi atau faktor-faktor lain yang dapat mempengaruhi. Menurut penelitian Mukhlis Kristiani pada tahun 2006 menyatakan bahwa umur tidak berhubungan secara signifikan terhadap kinerja petugas vaksinasi di Kabupaten Aceh Timur. Meskipun umur petugas cukup bervariasi ini tidak terlalu berpengaruh terhadap penyimpanan vaksin dalam cold chain / rantai dingin maupun sarana penyimpanan lain. ${ }^{15}$

Tabel 2 menunjukkan bahwa hampir seluruh petugas imunisasi merupakan tamat-an diploma, sehingga uji statistik tidak dapat dilakukan sebab ada satu kotak tabel dengan nilai frekuensi kenyataan sebesar 0 (Nol). Sehingga dapat disimpulkan bahwa dalam penelitian ini tingkat pendidikan petugas imunisasi tidak dapat diukur dan tidak dapat diketahui pengaruh tingkat pendidikan dengan praktik penyimpanan dan transportasi vaksin imunisasi di Puskesmas.
Mukhlis pada penelitiannya tahun 2006 menyatakan bahwa pendidikan tidak berhubungan secara signifikan terhadap kinerja petugas vaksinasi di Kabupaten Aceh Timur. Pendidikan petugas pengelola cold chain di Puskesmas di Kota Padang rata-rata sudah memenuh standar, sehingga dalam pengelolaan dan penyimpanan vaksin sebaiknya sesuai standar. ${ }^{15}$

Berdasarkan Tabel 2 dapat dilihat bahwa Puskesmas yang melaksanakan praktik yang baik terbanyak pada petugas imunisasi yang sudah bekerja lebih dari 1 tahun, sebanyak 9 petugas (56,3\%). Dari hasil uji statistik chi-square test dengan fisher's exact test diperoleh nilai $p=0,606(p>0,05)$ dapat disimpulkan bahwa tidak terdapat pengaruh yang signifikan antara masa kerja petugas imunisasi dengan praktik penyimpanan dan transportasi vaksin imunisasi di tingkat Puskesmas Kota Padang. Hal ini menunjukan bahwa praktik penyimpanan dan transportasi vaksin di Puskesmas dengan petugas yang masa kerja lebih dari satu tahun tidak benarbenar berbeda dengan petugas dengan masa kerja kurang dari satu tahun. Terdapat tujuh petugas $(43,7 \%)$ dengan masa kerja lebih dari satu tahun yang memiliki praktik buruk. Hal ini kemungkinan disebabkan karena kurangnya pengetahuan petugas imunisasi tentang penyimpanan dan transportasi vaksin imunisasi. Mukhlis menyatakan bahwa masa kerja tidak ada hubungan secara signifikan terhadap kinerja petugas vaksinasi di Kabupaten Aceh Timur. Meskipun masa kerja petugas cukup bervariasi ini tidak terlalu berpengaruhi terhadap penyimpanan vaksin dalam cold chain maupun sarana penyimpanan lainnya. ${ }^{15}$

Berdasarkan Tabel 2 dapat dilihat bahwa dari puskesmas dengan praktik yang baik terbanyak pada petugas imunisasi yang telah mendapat pelatihan pengelolaan vaksin, sebanyak 10 petugas $(58,8 \%)$. hasil uji statistik chi-square test dengan fisher's exact test diperoleh nilai $\mathrm{p}=1,000(\mathrm{p}>0,05)$ dapat disimpulkan bahwa tidak terdapat pengaruh yang signifikan antara pengalaman pelatihan petugas imunisasi dengan praktik penyimpanan dan transportasi vaksin imunisasi di tingkat puskesmas Kota Padang. Hal ini menunjukan bahwa pe-ngalaman 
Pelatihan tidak benar-benar menunjukan pengaruh terhadap praktik yang benar. Hal ini dapat disebabkan karena petugas tidak mengulang kembali materi-materi yang telah didapatkan dan petugas merasa cukup dengan hanya mengikuti satu pelatihan. Hasil ini sejalan dengan penelitian Bell et al yang menemukan tidak ada perbedaan bermakna pada kelompok kasus (mendapat pelatihan) dengan kelompok terkontrol (tidak mendapatkan pelatihan). ${ }^{16}$ Untuk meningkatkan pengetahuan dan/atau ketrampilan petugas imunisasi perlu dilakukan pelatihan sesuai dengan modul latihan petugas imunisasi. Pelatihan teknis diberikan kepada petugas imunisasi di puskesmas, rumah sakit dan tempat pelayanan lain, petugas cold chain di semua tingkat. Pelatihan manajerial diberikan kepada para pengelola imunisasi dan supervisor di semua tingkat. ${ }^{8}$ Mukhlis dalam penelitiannya pada tahun 2006 menyatakan bahwa pelatihan petugas tidak ada hubungan secara signifikan terhadap kinerja petugas vaksinasi di Kabupaten Aceh Timur. Dengan peningkatan kemampuan petugas dalam pengelolaan vaksin akan meningkatkan pengetahuan petugas dalam pengelolaan vaksin, sehingga penyimpanan vaksin sesuai standar dan dapat mencegah terjadinya kejadian ikutan pasca imunisasi. ${ }^{15}$

Berdasarkan hasil penelitian diketahui bahwa persentase praktik penyimpanan dan transportasi vaksin yang baik lebih banyak pada petugas imunisasi dengan pengetahuan baik (61,9\%) dibandingkan dengan yang memiliki pengetahuan kurang (38,1\%). Berdasarkan hasil uji statistik didapatkan adanya hubungan yang signifikan antara pengetahuan petugas imunisasi dengan praktik penyimpanan dan transportasi vaksin imunisasi di tingkat Puskesmas kota Padang tahun 2014 dengan nilai $p<0,05$.

Pengetahuan yang benar dan praktik rantai dingin di pelayanan kesehatan primer yang terlibat dalam imunisasi sangat penting. Dari hasil penelitian Shah yang dilakukan pada tahun 1994 tentang pengetahuan, sikap dan praktik dalam mengelola rantai dingin vaksin didapatkan hasil pengetahuan yang kurang dan praktik yang buruk. Dalam hal ini terbukti bahwa pengetahuan dan praktik tentang rantai dingin tidak memuaskan, sehingga dapat disimpulkan bahwa pengetahuan mempengaruhi praktik dalam pemeliharaan rantai dingin. ${ }^{17}$

Dari hasil penelitian Carlos dan Bjune pada tahun 2007 dalam membandingkan petugas pada kesehatan layanan primer harus memiliki pengetahuan yang baik untuk mengelola vaksin agar kualitas vaksin tetap terjaga mulai dari tempat produksi. Hasil penelitian di Niassa, didapatkan bahwa terdapat pengetahuan dan praktik yang buruk dalam mengelola vaksin imunisasi di pusat pelayanan primer. ${ }^{14}$ Hasil penelitian dari Yuan et al, didapatkan juga hubungan yang sama antara pengetahuan dan praktik di pelayanan kesehatan primer di Toronto. Dengan hasil 7 tenaga kesehatan (6\%) dengan pengetahuan baik dan 11 (10\%) praktik penyimpanan yang benar, sehingga dari hasil penelitian dapat disimpulkan bahwa terdapat pengetahuan tenaga kesehatan yang kurang dan praktik dalam penyimpanan dan transportasi vaksin yang tidak sesuai di praktik pelayanan kesehatan primer. ${ }^{18}$

\section{KESIMPULAN}

Lebih dari separuh responden memiliki pengetahuan yang baik mengenai penyimpanan dan transportasi di tingkat Puskesmas kota Padang.

Lebih dari separuh Puskesmas memiliki praktik yang baik mengenai penyimpanan dan transportasi di tingkat Puskesmas kota Padang.

Tidak adanya hubungan yang bermakna antara umur petugas imunisasi dengan praktik penyimpanan dan transportasi di tingkat Puskesmas kota Padang

Tidak adanya hubungan yang bermakna antara tingkat pendidikan petugas imunisasi dengan praktik penyimpanan dan transportasi di tingkat Puskesmas kota Padang

Tidak adanya hubungan yang bermakna antara masa kerja petugas imunisasi dengan praktik penyimpanan dan transportasi di tingkat Puskesmas kota Padang

Tidak adanya hubungan yang bermakna antara pengalaman pelatihan petugas imunisasi dengan praktik penyimpanan dan transportasi di tingkat Puskesmas kota Padang

Adanya hubungan yang bermakna antara pengetahuan petugas imunisasi dengan praktik 
penyimpanan dan transportasi di tingkat Puskesmas kota Padang

\section{UCAPAN TERIMA KASIH}

Terima kasih yang sedalam-dalamnya kepada kepala puskesmas dan staf yang sudah membantu penulis dalam penelitian ini.

\section{DAFTAR PUSTAKA}

1. IDAl. Pedoman imunisasi di Indonesia. Edisi ke-4. Satgas Imunisasi Ikatan Dokter Anak Indonesia. 2011.

2. Gazmararian JA, Oster NV, Green DC, Schuessler $\mathrm{L}$, Howell $\mathrm{K}$, Davis J, et al. Vaccine storage practice in primary care physician offices: assessment and intervention. Am J Prev Med. 2002; 23(4):246-53.

3. Centers for Disease Control and Prevention. Guidelines for maintaning and managing the vaccine cold chain. MMWR. 2003; 52(42): 102325.

4. Centers for Disease Control and Prevention. Vaccine storage and handling toolkit. National Center for Immunization and Respiratory Diseases. 2012.

5. Pickering LK, Wallace G, Rodewald L. Too hot, too cold: issues with vaccine storage. Pediatrics. 2006. 118:1738-9.

6. Centers for Disease Control and Prevention. Epidemiology and prevention of vaccinepreventable diseases. The pink book: course textbook. Edisi ke-12. 2012. Chapter 1: 4-7.

7. Kalsum U. Evaluasi distribusi dan penyimpanan vaksin di Dinas Kesehatan Kabupaten Majene Sulawesi Barat (tesis). Yogyakarta: Program Studi IImu Kesehatan Masyarakat. Program Pascasarjana Fakultas Kedokteran Universitas Gadjah Mada. 2011.

8. Depkes RI, Pedoman pengelolaan vaksin. Jakarta: Departemen Kesehatan RI; 2009. World Health
Organization. Immunization standards, national regulatory authorities. 2013 (diunduh 30 Desember 2013). Tersedia dari: URL: HYPERLINK http://www.who.int/immunization

standards/nationalregulatoryauthorities/role/en/inde x.html

9. Carlos J, Bjunne G. Cold chain management: knowledge and practices in primary health care facilities in Niassa, Mozambique. Ethiop J Health Dev. 2007(21):1-6

10. Widsanugorn O, Suwattana O, Harun M, Sakamoto J. Healthcare workers' knowledge and practices regarding expanded program immunization in Kalasin, Thailand. Nagoya J. Medical Science. 2011:(73):171-85.

11. Notoatmodjo S. Promosi kesehatan teori dan aplikasi. Jakarta: Rineka Cipta; 2007.

12. Kristini TD. Faktor-faktor risiko kualitas pengelolaan vaksin program imunisasi yang buruk di unit pelayanan swasta (studi kasus di Kota Semarang). Semarang: Program Pasca Sarjana Universitas Diponegoro; 2008.

13. Carlos J, Bjunne G. Cold chain management: knowledge and practices in primary health care facilities in Niassa, Mozambique. Ethiop J Health Dev 21, 2007: 1-6.

14. Mukhlis K. Hubungan faktor-faktor individu dan organisasi dengan kinerja petugas vaksinasi di Kabupaten Aceh Timur. WPS. 2006; 4.

15. Bell Karen N, Hogue CJ, Manning C, Kendal A. Risk factors for improper vaccine storage and handling in private provide offices. Pediatrics. 2001:107.

16. Shah RC. Knowledge, attitude and practice of maintenance of cold chain in immunization. Indian Pediatrics. 1993;31:454-6.

17. Yuan L, Daniels S, Naus M, Bricic B. Vaccine storage and handling. Knowledge and practice inprimary care physicians' offices. Can Fam Physician. 1995;41:1169-76. 